\title{
三峡澎溪河回水区流速对藻类原位生长速率的影响"
}

\author{
李 哲 ${ }^{1,2}$, 张曾宇 ${ }^{2}$,杨中华 ${ }^{3}$, 郭劲松 ${ }^{1}$, 刘 静 $^{2}$, 李 丹 $^{3}$, 肖 艳 ${ }^{1}$ \\ ( 1 : 中国科学院重庆绿色智能技术研究院,重庆 400030) \\ ( 2 : 重庆大学城市建设与环境工程学院, 重庆 400044) \\ $(3$ :武汉大学水资源与水电工程科学国家重点实验室,武汉 430072)
}

\begin{abstract}
摘 要: 为明晰不同流速水平对三峡支流回水区库湾藻类原位生长的影响, 本文采用可调速的环形实验槽, 选择三峡水 库不同运行状态 (低水位、高水位), 对三峡澎溪河高阳平湖库湾藻类生物量 (用叶绿素 $\mathrm{a}$ 浓度表示) 变化特征进行原位受 控实验. 通过流速在 0 (对照)、 $0.1 、 0.2$ 和 $0.3 \mathrm{~m} / \mathrm{s}$ 的实验发现, 夏季低水位阶段澎溪河水域光热充足, 但流速升高 $(>0.2$ $\mathrm{m} / \mathrm{s}$ ) 对藻类原位比生长速率具有一定影响. 大体上, 高阳平湖水域藻类原位比生长速率与流速水平呈对数关系. 冬季高 水位运行期间, 流速的升高将可能在一定程度上促进水柱扰动,成为维持藻类在上层水体受光生长、避免下沉的主要因 素.该时期,采用调节流速、流量的方法抑制藻类生长的难度相对较大.
\end{abstract}

关键词: 三峡库区;澎溪河;高阳平湖;生态槽;流速;控藻

\section{Effects of flow speed on the change of in situ growth rates of algae in Pengxi River back- water zone, Three Gorges Reservoir}

\author{
LI Zhe ${ }^{1,2}$, ZHANG Zengyu ${ }^{2}$, YANG Zhonghua ${ }^{3}$, GUO Jinsong ${ }^{1}$, LIU Jing ${ }^{2}$, LI Dan ${ }^{3} \&$ XIAO Yan ${ }^{1}$ \\ (1: Chongqing Institute of Green and Intelligent Technology, Chinese Academy of Sciences, Chongqing 400030, P. R. China) \\ (2: Faculty of Urban Construction and Environmental Engineering, Chongqing University, Chongqing 400044, P. R. China) \\ (3: State Key Laboratory of Water Resources and Hydropower Engineering Science, Wuhan University, Wuhan 430072, P. R. \\ China)
}

\begin{abstract}
To understand the influence of flow speed on algae growth rates in reservoirs, in situ experiment using stirring experimental tank was carried out in different water level periods (low water level and high water level) in Pengxi River backwater area, a tributary of the Three Gorges Reservoir. Four different treatments, i. e. flow speeds of $0,0.1,0.2$ and $0.3 \mathrm{~m} / \mathrm{s}$, were selected in the experiment. In summer low water level period, light and temperature conditions were feasible for the growth of algae. Increase in flow speed $(>0.2 \mathrm{~m} / \mathrm{s})$ would have significant impacts on the growth of algae. In general, relationships between algal growth rates and flow speeds were in accordance with logarithmic function. In winter, a high water level period, increasing in flow speed would increase in turbulence in water column, preventing sedimentation of algae. In this period, regulating flow speed and discharge to control algal growth might be difficult.
\end{abstract}

Keywords: Three Gorges Reservoir; Pengxi River; Lake Gaoyang; ecological tank; current velocity; controlling algae growth

在河流、水库等流动性水体,水动力条件是藻类生境的关键宏观物理参量, 既有研究表明水华暴发与水 动力条件呈显著相关 ${ }^{[1-3]}$. 王丽平等 ${ }^{[4]}$ 、王红萍等 ${ }^{[5]}$ 分别对水华频发的大宁河、汉江进行研究, 发现水流条件 是研究区内藻类暴发的主要诱导因素之一, 合适的流速条件能给藻类生长营造有利的外部环境. Acuna 等 ${ }^{[6]}$ 、Mitrovic 等 ${ }^{[7]}$ 分别对南美洲 Pampean 溪、大洋洲 Darling 河进行研究,指出较缓的流速能促进悬浮藻类 的生长,而过高的流速则抑制悬浮藻类的生长. 目前形成的共同观点是:适宜的水体流速有利于藻类不断得 到新的营养物质供应,并促进藻类的生长和繁殖. 过大的流速则会导致较大的剪应力和切变速率,不仅干扰

* 国家自然科学基金项目 $(51179125,51079105,51309220)$ 和中国科学院西部行动计划项目 (KZCX2-XB3-14) 联合资助. 2014-04-28 收稿;2014-12-29 收修改稿. 李哲(1981 ), 男,博士, 副研究员;E-mail:lizhe@ cigit. ac. cn. 
藻类在真光层中稳定受光生长, 甚至可能导致藻类细胞的破坏 ${ }^{[8]}$. 但是, 由于藻类生长、繁殖是一个多参数 协同作用的复杂过程, 实际水域中藻类同流速的函数关系受到其他生境参量的影响, 依然具有不确定性.

三峡水库成库以来支流回水区频繁出现的水华现象是近 10 年来我国水库生态学领域研究的热点. 尽 管目前已有不少研究发现特定流速范围对该水域藻类生长存在影响,但在 “蓄清排浑” 的水库运行状态下藻 类增殖同流速的定量关系及其在实际水体中的原位验证仍鲜有报道. 为明确水库不同运行阶段藻类原位生 长速率同流速大小的定量关系, 为确定水库生态调度的流速条件提供依据, 笔者所在团队曾对三峡水库中 段支流澎溪河高阳平湖水域藻类原位生长速率进行了初步研究 ${ }^{[9-11]}$, 在前期研究基础上,本研究拟采用环形 实验槽开展原位受控实验, 分析水库不同运行阶段 (高水位、低水位)下不同流速水平对槽中藻类生长的影 响,分析该水域特定水库运行阶段“调度控藻”方案所需达到的流速条件.

\section{1 材料与方法}

\section{1 研究区域}

澎溪河地处四川盆地东部边缘, 流域面积 $5173 \mathrm{~km}^{2}$, 干流全长 $182.4 \mathrm{~km}$. 高阳平湖水域 (图 1), 地处澎溪河下 游永久回水区中部,地势平坦,上游水体经峡谷流入此处,流速减缓,具有类似湖泊的地貌环境及水文水力特征. 该 水域在夏季低水位阶段平均水深不足 $15 \mathrm{~m}$, 冬季高水位阶段平均水深将超过 $40 \mathrm{~m}$,形成了近似于“浅水湖泊↔深 水湖泊” 的季节性交替特征. 本研究原位培养地点为高阳平湖李家坝处库湾内原位实验平台处 $\left(31^{\circ} 5^{\prime} 48^{\prime \prime} \mathrm{N}\right.$, $108^{\circ} 40^{\prime} 20^{\prime \prime} \mathrm{E}$ ), 该水域为半封闭性库湾, 常年水体流速范围为 $0 \sim 0.8 \mathrm{~m} / \mathrm{s}$, 水华期间通常流速不超过 $0.5 \mathrm{~m} / \mathrm{s}$.

\section{2 实验装置}

整个实验装置设计在浮排上, 通过绳索牵引漂浮于实验水域. 浮排尺寸为 $6 \mathrm{~m} \times 4 \mathrm{~m}$, 中间通过金属支架 连接. 实验装置悬挂在支架上并浸于水中, 共设计了 3 个环形实验槽 (图 2). 生态槽整体装置由外筒、内筒、 桨叶、电机及电机盒组成. 内筒与外筒间组成内径 $500 \mathrm{~mm}$ 、外径 $1000 \mathrm{~mm}$ 、高度 $2000 \mathrm{~mm}$ 的封闭盛水空间. 整 个结构件采用 $10 \mathrm{~mm}$ 厚亚克力板材制作, 内外筒为一次成型加工, 与底盖无缝熔接,保证整个装置的强度. 3 个实验槽中, 两个可以通过普通电机和多级差速控制装置调整桨叶转速, 驱动水体在槽中往复流动并获得 不同的流速梯度, 称为流速实验槽; 另一个为静置水体, 无流速调节功能, 称为对照槽. 安装时, 流速实验槽 和对照槽上缘位于水面上 $500 \mathrm{~mm}$,防止实验期间湖水进人槽内.

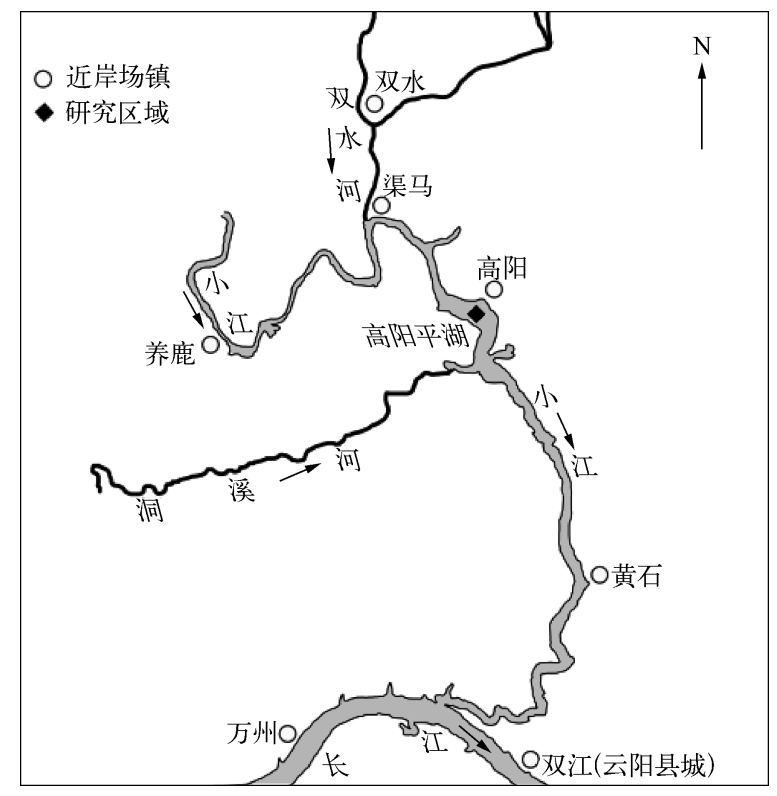

图 1 澎溪河回水区云阳段及高阳平湖示意

Fig. 1 Backwater area of the Pengxi

River and Lake Gaoyang

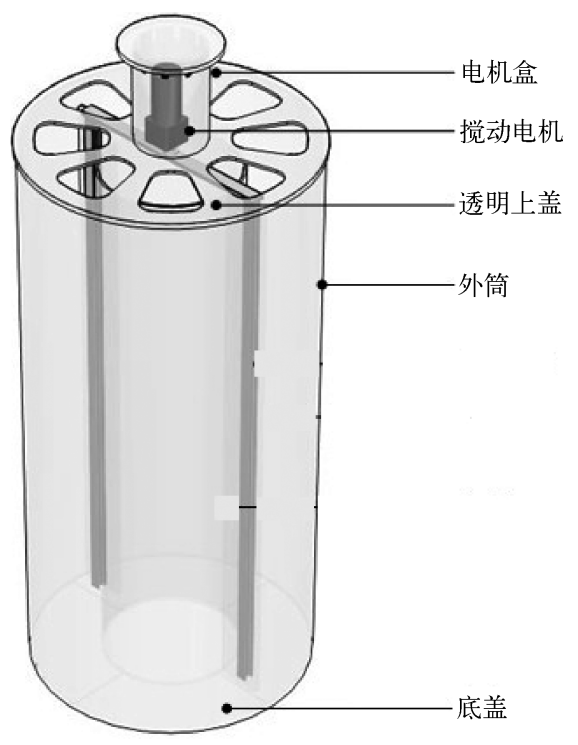

图 2 流速实验槽

Fig. 2 Experimental tank 


\section{3 原位实验方法}

原位实验时间分别选择在水库低水位阶段 (2011 年 6 月底至 7 月初) 和高水位阶段 (2011 年 11 月底至 12 月初), 分别代表了三峡水库澎溪河回水区两种典型的生境特征 ${ }^{[9-11]}$ :

1) 低水位阶段: 为藻类生长季节, 光热与营养物输人均满足藻类生长的基本需求, 但同期为汛期, 不稳 定的水动力条件限制了藻类的生长;

2) 高水位阶段: 水位升高在一定程度上为藻类创造了相对稳定的水动力条件, 但水温下降, 限制藻类生 长, 使其逐渐进人冬季非生长季节. 不少藻类将因为活性下降而逐渐下沉.

根据前期该水域流速监测结果, 确定原位实验的 3 个流速水平分别为 $0.1 、 0.2$ 和 $0.3 \mathrm{~m} / \mathrm{s}$, 以静置且透 明的对照槽 (流速为 $0 \mathrm{~m} / \mathrm{s}$ ) 和桶外高阳平湖库湾水体为对照. 为确保实验结果可靠, 每个流速水平均采用 2 个流速实验槽同步开展平行观测. 本实验的基本假设是在富营养条件下流速可能对藻类生长产生影响, 故 整个实验期间暂不考虑营养物限制或外源性营养物补充对藻类生物量的贡献.

根据 Trimbee 等 ${ }^{[12]}$ 和 Gaedeke 等 ${ }^{[13]}$ 的观点, 藻类群落结构 (多样性和演替速率) 对外界扰动响应显著的 时段为 $5 \sim 15 \mathrm{~d}$; 另外, Reynolds ${ }^{[14]}$ 研究表明淡水湖泊中藻类世代周期一般为 $3 \sim 4 \mathrm{~d}, 2 \sim 3$ 倍于世代周期的 时间间隔 $(6 \sim 16 \mathrm{~d})$ 易于反映藻类群落演替特征. 故综合考虑选择实验周期为 $7 \mathrm{~d}$, 每 $24 \mathrm{~h}$ 采样 1 次, 采样时 间控制在 9:30-12:00. 为防止实验槽外表滋长水绵等附着性藻种, 产生遮光效应并对实验造成不利影响, 实验前对实验槽外筒进行酸洗, 实验期间每天下午对实验槽水下部分外表进行刷洗.

绝大多数藻类种群增长符合指数增长模型:

$$
N_{t}=N_{0} \cdot e^{\mu \cdot t}
$$

式中, $N_{t}$ 为 $t$ 时刻藻类生物量; $N_{0}$ 为初始藻类生物量, 本研究选择叶绿素 a (Chl. a ) 浓度作为藻类生物量估算 的测量指标. 所获得的藻类原位受控生长速率为实验槽中的比生长速率. 上述公式可进一步转换为:

$$
\mu=\frac{\log _{2}\left(X_{2} / X_{1}\right)}{t}
$$

式中, $\mu$ 为藻类原位比生长速率 $\left(\mathrm{d}^{-1}\right), X_{i}$ 为 $i$ 时刻 Chl. a 的质量浓度 $\left(\mathrm{mg} / \mathrm{m}^{3}\right), t$ 为采样时间 $(\mathrm{d})$. 研究中, 不 扣除对照的生长速率以桶外高阳平湖湖水中藻类比生长速率为参照, 而扣除对照的比生长速率则以对照槽 内 $0 \mathrm{~m} / \mathrm{s}$ 流速时藻类比生长速率为参照.

\section{4 水体理化指标测定}

流速实验槽内流速水平为平均流速, 采用槽内上、中、下 3 个深度与内环、外环 2 个垂线共 6 个测点的流 速数据取平均值后获得相应工况的平均流速水平.

使用 $5 \mathrm{~L}$ 改良式采水器采集水样, 采集槽内 $0.5 、 1.2$ 和 $2.0 \mathrm{~m} 3$ 个水层深度处的水样, 等量混合后于 $48 \mathrm{~h}$ 内完成全部样品分析. 现场同步测试实验槽内和湖水的各项生态指标. 溶解氧 ( DO) 采用 $\mathrm{YSI}^{\circledR}$ Pro ODO 测定, 水温和 $\mathrm{pH}$ 值采用 $\mathrm{YSI}^{\circledR} 63$ 测定, 水下光强采用 $\mathrm{Li}-\mathrm{COR}^{\circledR} 192 \mathrm{SA}$ 测定,光衰减系数 $\left(K_{\mathrm{d}}\right)$ 按照文献 $[15]$ 的方法测定. 正午光强由现场科研级气象站所配置的 $\mathrm{Li}-\mathrm{COR}^{\circledR} 190$ 光量子仪测定.

室内测定指标有: Chl. a 、铵态氮 $\left(\mathrm{NH}_{4}^{+}-\mathrm{N}\right)$ 、硝态氮 $\left(\mathrm{NO}_{3}^{-}-\mathrm{N}\right)$ 、溶解性反应磷 $(\mathrm{SRP})$ 、总氮 $(\mathrm{TN})$ 和总磷 (TP) 浓度. 所有化学测定指标分析方法参照《水和废水监测分析方法 (第四版) 》进行 ${ }^{[16]}$.

\section{5 数据处理与统计方法}

所有数据均录人 SPSS ${ }^{\circledR}$ 软件进行统计分析. 采用 Spearman 相关性分析说明数据间变化的线性相关性. 采用 Kruskal-Wallis 分析说明数据间差异显著性. 采用 Origin ${ }^{\circledR}{ }^{\circledR}$ 软件进行作图.

\section{2 结果与分析}

\section{1 水库不同运行阶段藻类原位生长速率特征}

低水位阶段, 对照槽内水体 Chl. a 浓度变化相对平缓, 而流速实验槽中水体 Chl. a 浓度则呈现较显著的变 化. 流速为 $0.3 \mathrm{~m} / \mathrm{s}$ 时, 流速实验槽中 Chl. a 浓度经历了首先迅速升高而后迅速下降的大波动, 藻类在实验第 $2 、 3$ $\mathrm{d}$ 的生物量最大, 达到 $60 \sim 70 \mu \mathrm{g} / \mathrm{L}$, 而后在第 $5 \mathrm{~d}$ 迅速下降至原位实验期间最低水平 $(11.3 \mu \mathrm{g} / \mathrm{L})$, 在第 $6 、 7$ 
d Chl. a 浓度逐步回升. 流速为 $0.2 \mathrm{~m} / \mathrm{s}$ 时, 流速实验槽中 Chl. a 浓度在第 $4 \mathrm{~d}$ 达到峰值 $(50.8 \mu \mathrm{g} / \mathrm{L})$, 而后缓 慢下降, 其变化幅度显著小于 $0.3 \mathrm{~m} / \mathrm{s}$ 流速组. 在流速为 $0.1 \mathrm{~m} / \mathrm{s}$ 时, 同对照槽相比, 流速实验槽前 $3 \mathrm{~d}$ Chl. a 浓度变化趋势与其相一致, 而从第 $4 \mathrm{~d}$ 开始 Chl. a 浓度出现了较显著的升高, 在第 $5 \mathrm{~d}$ 达到峰值 $(72.4 \mu \mathrm{g} / \mathrm{L})$, 虽然第 $6 、 7 \mathrm{~d}$ 出现下降,但总体上流速实验槽 Chl. a 浓度显著高于对照槽, 上述趋势与高阳平 湖中 Chl. a 浓度的同期变化过程一致 (图 3 ).

高水位阶段为藻类非生长季节. 研究期间, 对照槽同流速实验槽内的藻类变化并未呈现明显特征, 但对 照槽内 Chl. a 浓度变化与高阳平湖湖水中的呈极显著正相关 $\left(R^{2}=0.906, P \leqslant 0.01\right)$. 比较发现, 在流速为 $0.3 \mathrm{~m} / \mathrm{s}$ 时, 流速实验槽中藻类 Chl. a 浓度水平基本保持平稳, 甚至出现略微增长的趋势. 但对照槽和高阳平 湖湖水中的 Chl. a 浓度则呈现显著下降的趋势, 在第 $6.7 \mathrm{~d}$ 降至最低. 在流速为 $0.2 \mathrm{~m} / \mathrm{s}$ 时, 流速实验槽内 Chl. a 浓度在第 $3 \mathrm{~d}$ 出现第一个峰值 $(2.7 \mu \mathrm{g} / \mathrm{L})$, 此后略有下降, 而后又略有升高. 虽然对照槽和高阳平湖湖 水中的 Chl. a 浓度总体仍呈下降趋势, 但该阶段 Chl. a 浓度下降趋势显著弱于 $0.3 \mathrm{~m} / \mathrm{s}$ 流速组的下降趋势. 在流速为 $0.1 \mathrm{~m} / \mathrm{s}$ 时, 流速实验槽内藻类呈现出较显著的增长趋势, 在第 $2 \sim 3 \mathrm{~d}$ 时增长较为明显, 第 $4 \mathrm{~d}$ 后 的变化趋势与高阳平湖湖水、对照槽基本一致. 而高阳平湖湖水和对照槽内 Chl. a 浓度在第 $2 \mathrm{~d}$ 保持相对较 高水平后出现显著下降,但在第 $4 \mathrm{~d}$ 后出现逐渐回升的趋势 ( 图 3 ).

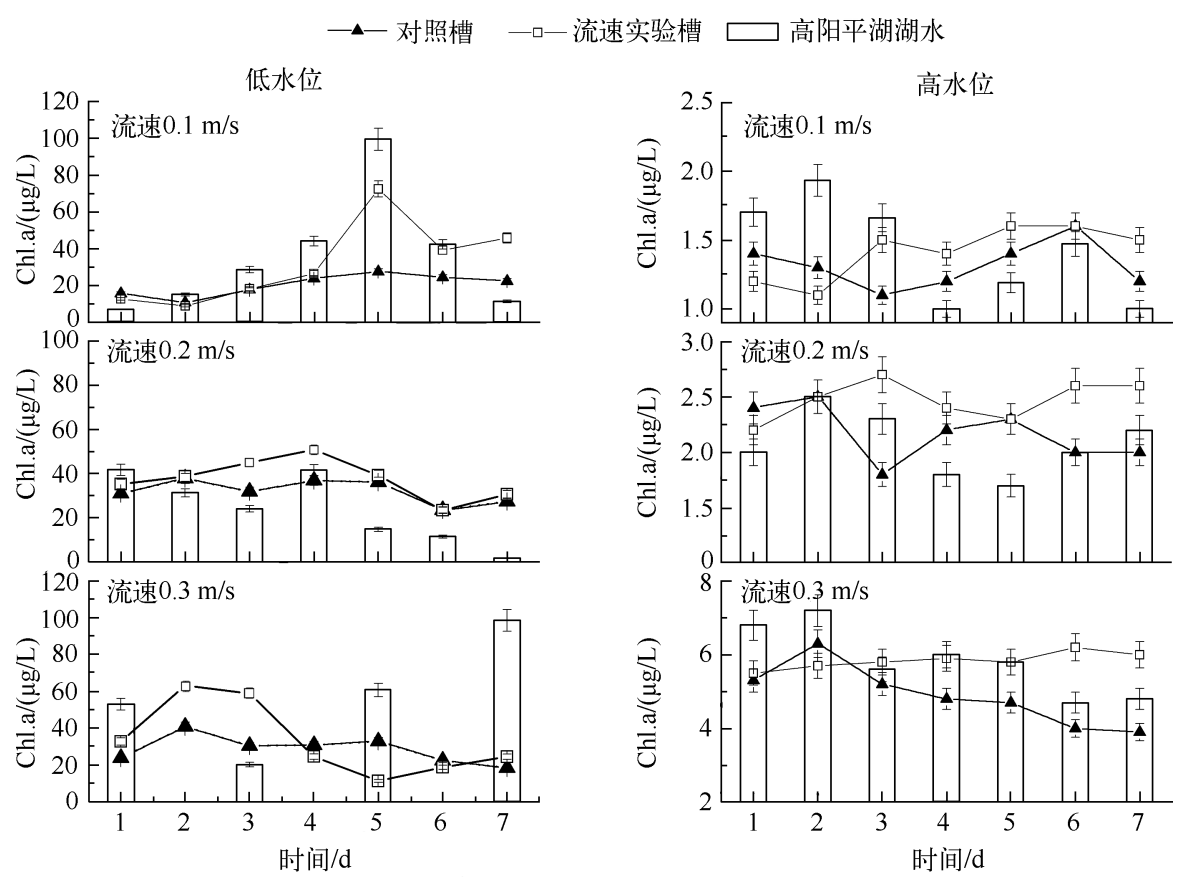

图 3 不同水位实验槽中 Chl. a 浓度的变化过程

Fig. 3 Changes of Chl. a concentrations in the experimental tanks with different water levels

研究期间, 不同流速水平下的每日藻类原位比生长速率的均值见图 4. 比较分析可以看出, 低水位阶段, 随着 实验流速从 $0.1 \mathrm{~m} / \mathrm{s}$ 逐渐升高到 $0.3 \mathrm{~m} / \mathrm{s}$, 流速实验槽中藻类比生长速率从 $0.26 \mathrm{~d}^{-1}$ 逐渐下降到 $-0.10 \mathrm{~d}^{-1}$, 表 现出指数变化的下降趋势. 根据图 4 的结果, 采用对数函数形式对流速水平和实验槽中藻类比生长速率的 变化进行拟合 :

$$
\left\{\begin{array}{l}
\mu=0.337 \ln (v)-0.532\left(R^{2}=0.965, P \leqslant 0.01, \text { 不扣除对照, } 0.1 \leqslant v \leqslant 0.3\right) \\
\mu=0.224 \ln (v)-0.337\left(R^{2}=0.962, P \leqslant 0.01 \text {, 扣除对照, } 0.1 \leqslant v \leqslant 0.3\right)
\end{array}\right.
$$

拟合结果表明, 水库低水位运行条件下流速实验槽中藻类比生长速率同流速水平呈对数关系, 拟合结 果显著且有效. 该对数模型可以用于预测不同流速下的藻类比生长速率. 
从高水位阶段生长速率的计算结果可以看出, 随着实验流速从 $0.1 \mathrm{~m} / \mathrm{s}$ 升高到 $0.3 \mathrm{~m} / \mathrm{s}$, 流速实验槽中 藻类比生长速率从 $0.046 \mathrm{~d}^{-1}$ 下降到 $0.018 \mathrm{~d}^{-1}$, 表现出近似直线变化的下降趋势 (图 4). 为与低水位的拟合 模型相互匹配,采用对数函数形式对流速水平和流速实验槽中藻类比生长速率的变化进行拟合:

$$
\mu=0.0246 \ln (v)-0.0091\left(R^{2}=0.938, P \leqslant 0.01 \text {, 不扣除对照, } 0.1 \leqslant v \leqslant 0.3\right)
$$

拟合结果显著且有效. 该对数模型可以用于预测高水位下藻类的比生长速率.

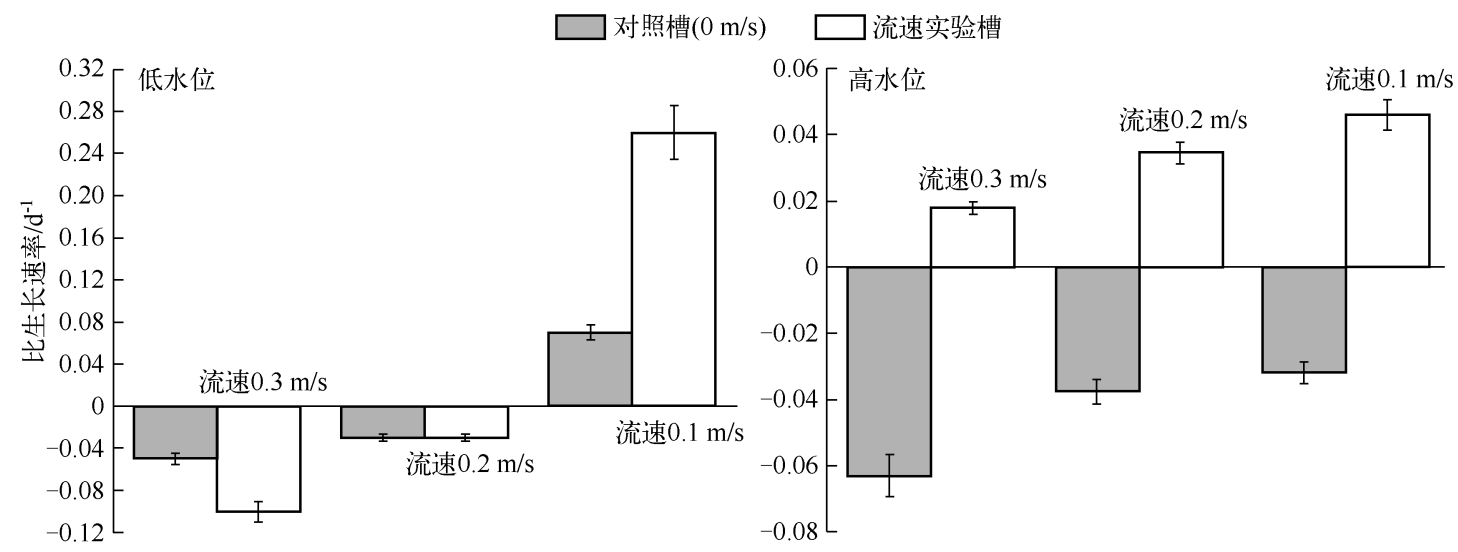

图 4 不同水位实验槽内藻类比生长速率变化

Fig. 4 Specific growth rates of algae in the experimental tanks with different water levels

\section{2 环境要素}

在藻类生长季节, 三峡水库位于汛期低水位运行状态, 澎溪河回水区水体滞留时间相对较短, 总体上呈 河流型一过渡型特征. 适宜的光热条件和湖水中相对丰富的氮、磷营养盐为藻类生长创造了相对优越的生境 条件, 但不稳定的水动力特征将对澎溪河回水区藻类生长产生影响. 藻类非生长季节, 三峡水库位于枯水季 节高水位运行状态, 水温下降和太阳辐射强度的下降使藻类生长受到极大的限制, 同时澎溪河回水区水体 滞留时间极大延长, 总体上呈湖泊型特征 ${ }^{[9,17-18]}$.

低水位阶段正午光强均值为 $43277 \pm 14913 \mathrm{~lx}$; 水温较高, 均值为 $29.00^{\circ} \mathrm{C}$, 变化范围为 $24.20 \sim 32.64^{\circ} \mathrm{C}$; 水体中无机悬浮泥沙浓度较高, 故 $K_{\mathrm{d}}$ 值较大, 均值为 $2.39 \mathrm{~m}^{-1}$, 变化范围为 $1.34 \sim 4.58 \mathrm{~m}^{-1} ; \mathrm{pH} 、 \mathrm{DO}$ 和 $\mathrm{NH}_{4}^{+}-\mathrm{N}$ 浓度的变化范围分别为 7. $90 \sim 9.51 、 4.20 \sim 13.48 \mathrm{mg} / \mathrm{L}$ 和 $0 \sim 0.690 \mathrm{mg} / \mathrm{L}$; TN 浓度均值为 $1.148 \mathrm{mg} / \mathrm{L}$, 超过国际公认的发生富营养化的浓度水平 $(0.2 \mathrm{mg} / \mathrm{L})$; TP 浓度均值为 $0.077 \mathrm{mg} / \mathrm{L}$, 超过国际 公认发生富营养化的浓度水平 $(0.02 \mathrm{mg} / \mathrm{L})^{[19]}$. 高水位研究阶段正午光强为 $37073 \pm 7075 \mathrm{~lx}$; 水温较低, 均值 为 $13.45^{\circ} \mathrm{C}$, 变化范围为 $10.50 \sim 17.80^{\circ} \mathrm{C}$; 水体中 $K_{\mathrm{d}}$ 值较小, 均值为 $0.60 \mathrm{~m}^{-1}$, 变化范围为 $0.41 \sim 0.81 \mathrm{~m}^{-1}$; $\mathrm{TN}$ 浓度均值为 $1.901 \mathrm{mg} / \mathrm{L} ; \mathrm{TP}$ 浓度均值为 $0.361 \mathrm{mg} / \mathrm{L}$, 磷素形态以溶解性磷为主 (表 1 ).

\section{3 讨论}

\section{1 低水位时期流速对藻类生长的影响}

原位培养下,槽内影响藻类生长的因素同槽外天然水体的区别主要是营养盐和水动力条件,但由于实 验期间 TN 和 TP 浓度较高, 水体呈现富营养化状态, 故可认为 TN、TP 浓度并不能够对藻类生长产生绝对限 制, 故研究结果能够用于反映水动力条件改变对澎溪河回水区藻类生长的影响. 研究期间, 流速实验槽、对 照槽内 DO 与 Chl. a 浓度呈显著正相关 $\left(R^{2}=0.623, P \leqslant 0.01\right) ; \mathrm{NH}_{4}^{+}-\mathrm{N} 、 \mathrm{NO}_{3}^{-}-\mathrm{N} 、 \mathrm{SRP}$ 等藻类主要利用的营养 盐浓度日变化过程亦在很大程度上受到 Chl. a 浓度的影响. $\mathrm{NO}_{3}^{-}-\mathrm{N}$ 和 $\mathrm{SRP}$ 处于低浓度水平 (甚至无法检 出). 流速实验槽中的 $\mathrm{NO}_{3}^{-}-\mathrm{N}$ 浓度表现为: $0.1 \mathrm{~m} / \mathrm{s}$ 流速组 $>0.2 \mathrm{~m} / \mathrm{s}$ 流速组 $>0.3 \mathrm{~m} / \mathrm{s}$ 流速组; $\mathrm{TP}$ 浓度表现 为: $0.1 \mathrm{~m} / \mathrm{s}$ 流速组 $>0.3 \mathrm{~m} / \mathrm{s}$ 流速组 $>0.2 \mathrm{~m} / \mathrm{s}$ 流速组; $\mathrm{NH}_{4}^{+}-\mathrm{N}$ 和 TN 浓度表现为: $0.3 \mathrm{~m} / \mathrm{s}$ 流速组 $>0.1 \mathrm{~m} / \mathrm{s}$ 
流速组 $>0.2 \mathrm{~m} / \mathrm{s}$ 流速组. 流速与同槽中营养盐浓度变化并没有必然联系.

表 1 实验期间水体理化指标

Tab. 1 Physical-chemical indicators of water during the research

\begin{tabular}{|c|c|c|c|c|c|c|}
\hline \multirow{2}{*}{ 指标 } & \multicolumn{3}{|c|}{ 低水位 } & \multicolumn{3}{|c|}{ 高水位 } \\
\hline & 流速实验槽 & 对照槽 & 湖水 & 流速实验槽 & 对照槽 & 湖水 \\
\hline 水温 $/{ }^{\circ} \mathrm{C}$ & $29.24 \pm 1.44$ & $29.35 \pm 1.47$ & $28.42 \pm 1.68$ & $13.47 \pm 2.66$ & $13.45 \pm 2.60$ & $13.43 \pm 2.62$ \\
\hline$K_{\mathrm{d}} / \mathrm{m}^{-1}$ & $2.57 \pm 0.65$ & $2.20 \pm 0.47$ & $2.40 \pm 0.73$ & $0.62 \pm 0.11$ & $0.59 \pm 0.10$ & $0.58 \pm 0.08$ \\
\hline pH 值 & $8.52 \pm 0.22$ & $8.63 \pm 0.31$ & $8.29 \pm 0.46$ & $8.00 \pm 0.12$ & $7.92 \pm 0.34$ & $8.31 \pm 0.39$ \\
\hline $\mathrm{DO} /(\mathrm{mg} / \mathrm{L})$ & $9.16 \pm 2.37$ & $8.73 \pm 1.80$ & $8.02 \pm 2.02$ & $8.00 \pm 0.17$ & $7.63 \pm 0.36$ & $7.49 \pm 0.35$ \\
\hline $\mathrm{NH}_{4}^{+}-\mathrm{N} /(\mathrm{mg} / \mathrm{L})$ & $0.192 \pm 0.183$ & $0.177 \pm 0.208$ & $0.288 \pm 0.203$ & $0.255 \pm 0.058$ & $0.271 \pm 0.053$ & $0.363 \pm 0.087$ \\
\hline $\mathrm{NO}_{3}^{-}-\mathrm{N} /(\mathrm{mg} / \mathrm{L})$ & $0.235 \pm 0.359$ & $0.088 \pm 0.131$ & $0.416 \pm 0.411$ & $1.000 \pm 0.174$ & $1.194 \pm 0.191$ & $1.301 \pm 0.233$ \\
\hline $\mathrm{TN} /(\mathrm{mg} / \mathrm{L})$ & $1.155 \pm 0.536$ & $1.039 \pm 0.273$ & $1.258 \pm 0.418$ & $1.748 \pm 0.302$ & $1.903 \pm 0.270$ & $2.036 \pm 0.195$ \\
\hline $\mathrm{TP} /(\mathrm{mg} / \mathrm{L})$ & $0.081 \pm 0.085$ & $0.047 \pm 0.038$ & $0.106 \pm 0.074$ & $0.302 \pm 0.022$ & $0.400 \pm 0.057$ & $0.375 \pm 0.092$ \\
\hline $\mathrm{SRP} /(\mathrm{mg} / \mathrm{L})$ & $0.011 \pm 0.017$ & $0.007 \pm 0.020$ & $0.007 \pm 0.008$ & $0.234 \pm 0.045$ & $0.337 \pm 0.051$ & $0.346 \pm 0.095$ \\
\hline
\end{tabular}

同对照槽相比, 流速自 $0.1 \mathrm{~m} / \mathrm{s}$ 升高到 $0.3 \mathrm{~m} / \mathrm{s}$ 时, 实验周期内藻类比生长速率呈指数下降, 说明流速升 高至 $0.3 \mathrm{~m} / \mathrm{s}$ 时将对藻类生长产生一定抑制. 进一步分析发现, 当流速位于中 $(0.2 \mathrm{~m} / \mathrm{s})$ 、低流速 $(0.1 \mathrm{~m} / \mathrm{s})$ 水平时,流速实验槽、对照槽中 Chl. a 浓度的日变化过程总体上同高阳平湖湖水中的一致,而当流速升高至 $0.3 \mathrm{~m} / \mathrm{s}$ 时, 流速实验槽中 Chl. a 浓度的日变化过程同高阳平湖湖水中的差异明显, 且流速实验槽的波动幅 度远高于对照槽,证实了前述关于在 $0.3 \mathrm{~m} / \mathrm{s}$ 流速下藻类生长受到一定程度抑制的推断.

低流速 $(0.1 \mathrm{~m} / \mathrm{s})$ 水平下, 流速实验槽中藻类长势优于对照槽; 在中流速 $(0.2 \mathrm{~m} / \mathrm{s})$ 水平下, 流速实验槽 中藻类比生长速率同对照槽基本一致. 这在一定程度上说明适宜的流速水平有利于藻类生长. 小规模的水 流扰动对藻类的生长和繁殖有利, 对光照造成的波动小, 不同流速条件下 $K_{\mathrm{d}}$ 值表现为: $0.3 \mathrm{~m} / \mathrm{s}$ 流速组 $>0.2 \mathrm{~m} / \mathrm{s}$ 流速组 $>0.1 \mathrm{~m} / \mathrm{s}$ 流速组, 但并不具有显著相关性 $(P>0.05)$. 适宜的流速可以增加藻细胞与周围 介质的营养、代谢产物的交换速率, 使藻类不断得到新的营养盐供应, 从而提高生产力和光合作用效 率 ${ }^{[20-21]}$. 除此之外,小规模的水流扰动可以使悬浮质中的一些氮、磷营养元素释放到水体中,使得水中可利 用的氮、磷浓度保持较高的水平 ${ }^{[22]}$. 低水位阶段水体呈现富营养化状态, 营养盐充足,所以认为水体扰动所 影响的受光均匀程度可能是藻类生长的限制因子. 对照槽为无流速静置水槽, 虽然藻类生长所受到的光热 条件和营养盐水平同自然环境条件接近,但在无流速静置状态下藻类细胞将出现下沉,进而因受光不足而 生长放缓. 镜检结果发现, 研究期间藻类群落主要为无鞭毛群体生长型绿藻 (实球藻, Pandorina morum 等), 无自我调节的悬浮生长机制,故在实验期间可能出现下沉、生长放缓.

\section{2 高水位时期流速对藻类生长的影响}

相对静置的水柱迫使活性下降的藻类细胞逐渐下沉,表层水柱 Chl. a 浓度呈现逐渐下降的趋势. 此时流 速的升高将可能在一定程度上促进水柱扰动, 成为维持藻类在上层水体受光生长的主要因素. 在这样的情 况下流速介人有助于藻类生长, 故在适宜的流速条件下藻类比生长速率呈现升高的趋势 (比生长速率为 正). 但随着流速的升高 (如 $0.3 \mathrm{~m} / \mathrm{s}$ ), 藻类受光生长将受到一定程度的影响, 在此条件下藻类比生长速率显 著下降,但仍然维持在正值. 对流速实验槽营养盐同步跟踪观测结果发现,TN、TP、SRP 浓度表现为: $0.3 \mathrm{~m} / \mathrm{s}$ 流速组 $>0.1 \mathrm{~m} / \mathrm{s}$ 流速组 $>0.2 \mathrm{~m} / \mathrm{s}$ 流速组; $\mathrm{NO}_{3}^{-}-\mathrm{N}$ 和 $\mathrm{NH}_{4}^{+}-\mathrm{N}$ 浓度表现为: $0.3 \mathrm{~m} / \mathrm{s}$ 流速组 $>0.2 \mathrm{~m} / \mathrm{s}$ 流速 组 $>0.1 \mathrm{~m} / \mathrm{s}$ 流速组. $0.3 \mathrm{~m} / \mathrm{s}$ 流速促进同槽中营养盐浓度的升高. 不同流速条件下的 $K_{\mathrm{d}}$ 值呈现显著差异 $(P \leqslant 0.01)$, 水体扰动所影响的受光均匀程度仍可能是藻类生长的限制因子.

故在冬季高水位蓄水阶段,采用调节流速、流量的方法抑制藻类生长的难度相对较大. 虽然目前从水体 流速与藻类生长的定量研究中得到了经验公式, 但对流速与藻类之间的定量关系描述并不成熟. 为更好地 描述和量化流速变化对藻类生长的外部环境和自身发展的影响,下一阶段应从机理层面研究流速对藻类的 影响和作用机制. 


\section{4 参考文献}

[ 1 ] Arlmnditsis GB, Stow CA, Paed HW et al. Delineation of the role of nutrient dynamics and hydrologic forcing on phytoplankton patterns along a freshwater-marine continuum. Ecological Modelling, 2007, 208(2) : 230-246.

[ 2 ] Gameiro C, Cartaxana P, Brolas V. Environmental drivers of phytoplankton distribution and composition in Tagus Estuary, Portugal. Estuarine Coastal and Shelf Science, 2007, 75(1) : 21-34.

[ 3 ] Becker V, Huszer VLM, Crossetti LO. Responses of phytoplankton functional groups to the mixing regime in a deep subtropical reservoir. Hydrobiologia, 2009, 28(1) : 137-151.

[4] 王丽平, 郑丙辉, 张佳否等. 三峡水库蓄水后对支流大宁河富营养化特征及水动力的影响. 湖泊科学, 2012,24(2): 232-237. DOI 10. 18307/2012.0210.

[5] 王红萍, 夏 军, 谢 平等. 汉江水华水文因素作用机理一一基于藻类生长动力学的研究. 长江流域资源与环境, 2004,13 (3) :282-285.

[6] Acuna V, Vilehes C, Giorgi A. As productive and slow as a stream can be the metabolism of a Pampean stream. Journal of the North American Benthological Society, 2011, 30(1) : 71-83.

[ 7 ] Mitrovic SM, Lorraine H, Fomgh D. Use of flow management to mitigate cyanobacterial blooms in the Lower Darling River, Australia. Journal of Plankton Research, 2011, 33(2) : 229-241.

[8] 吴晓辉,李其军. 水动力条件对藻类影响的研究进展. 生态环境学报,2010,19(7):1732-1738.

[9] 李 哲,方 芳, 郭劲松等. 三峡小江(澎溪河) 藻类功能分组及其季节演替特点. 环境科学, 2011,32(2):392-400.

[10］李 哲, 谢 丹, 郭劲松等. 三峡水库澎溪河典型优势藻原位生长速率的初步研究. 湖泊科学, 2012,24(5):746754. DOI 10. 18307/2012.0516.

[11] 冯 婧, 李 哲, 间 涁等. 三峡水库不同运行阶段澎溪河典型优势澡原位生长速率研究. 湖泊科学, 2014,26(2): 235-242. DOI 10. 18307/2014.0210.

[12] Trimbee AM, Harris GP. Use of time-series analysis to demonstrate advection rates of different variables in a small lake. Journal of Plankton Research, 1983, 5(6): 819-833.

[13] Gaedeke A, Sommer U. The influence of the frequency of periodic disturbances on the maintenance of phytoplankton diversity. Oecologia, 1986, 71(1): 25-28.

[14] Reynolds CS. Scales of disturbance and their role in plankton ecology. Hydrobiologia, 1993, 249(1/2/3): 157-171.

[15] 张运林,秦伯强,陈伟民等. 太湖水体光学衰减系数的特征及参数化. 海洋与湖沼, 2004,35(3):209-213.

[16] 国家环境保护总局《水和废水监测分析方法》编委会. 水和废水监测分析方法: 第 4 版. 北京: 中国环境科学出版 社, $2002: 88-284$.

[17］李 哲,方 芳, 郭劲松等. 三峡小江回水区段 2007 年春季水华与营养盐特征. 湖泊科学,2009,21(1):36-44. DOI 10. 18307/2009.0105.

[18］方 芳, 周 红, 李 哲等. 三峡小江回水区真光层深度及其影响因素分析. 水科学进展,2010,21(1):113-119.

[19］金相灿,刘淑坤,张宗涉等.中国湖泊环境. 北京:海洋出版社,1995.

[20］颜润润,逢 勇,赵 伟等. 环流型水域水动力对藻类生长的影响. 中国环境科学,2008,28(9):813-817.

[21] Grobbelaar JU. Turbulence in mass algal cultures and the role of light/dark fluctuations. Journal of Applied Phycology, $1994,6(3)$ : 331-335.

[22] 吴晓辉,李其军. 水动力条件对藻类影响的研究进展. 生态环境学报,2010,19(7):1732-1738. 